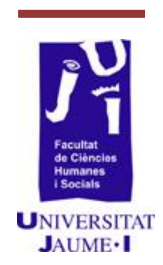

\title{
El cine posclásico en la cuerda floja de la no linealidad El espejismo de lo real frente al empirismo del MRI
}

Teresa Sorolla Romero tsorollaromero@gmail.com 
El trabajo que presentamos pretende constituir una aproximación al sentido de las películas de narrativa no lineal, que presentan el argumento alterado cronológicamente o bien desde diferentes puntos de vista o focalizaciones, forzando al espectador a ordenar las secuencias o interpretar las diversas focalizaciones. Así, en él recae la responsabilidad de sostener y construir el sentido final del relato.

Partimos de conceptos filosóficos que definen la Modernidad y la Posmodernidad y permiten adscribir, por un lado, el Modo de Representación Institucional, modelo de representación hegemónico en el cine comercial, a las películas lineales que presentan un relato sin grietas de cara al espectador, que le ofrecen un mundo con sentido completo en base a una realidad no problemática, utilizando unas reglas que éste decodifica (inconscientemente) mediante la razón empírica. Por otro lado, consideraremos postmodernas las películas no lineales que rompen con la idea (moderna) de Historia unitaria y progresiva y hacen ver al espectador que los relatos son un constructo en base a determinadas selecciones representativas y reglas, es decir, que los discursos (en este caso el MRI) no son naturales sino interesados.

No obstante, hay películas no lineales donde el espectador puede reconstruir las secuencias "desordenadas" y conseguir tras este esfuerzo cognitivo fortalecer el relato clásico, unitario, aval de un mundo consistente. Por eso acudiremos al concepto psicoanalítico de lo real entendido como angustia, como malestar irrepresentable, como aquello que no podemos entender de la realidad, y defenderemos, tras hacer análisis textual, que las películas fragmentadas formalmente que infunden este malestar, sí que contribuyen a hacer ver al espectador que el Modo de Representación Institucional, vigente no sólo en las industrias culturales, sino también en los medios de comunicación que configuran la agenda de la opinión pública, no es natural sino configurado en base a unas intenciones concretas. Que el mundo es mucho más complejo y, tal y como la Posmodernidad revela, imposible de comprender desde una única perspectiva.

Palabras clave: Modernidad, Posmodernidad, MRI, trama, argumento, focalización, lo real, Historia, razón empírica.

\section{Introducción}

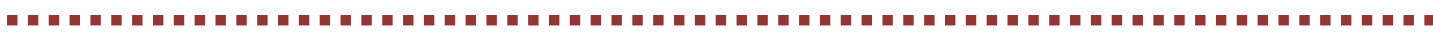

El artículo pretende hacer de puente entre filosofía y representación cinematográfica, enlazando la teoría tanto de un campo como del otro con la práctica del análisis textual, con el fin de dar un sentido a la 
narrativa de películas que se salen del modo narrativo hegemónico en el

cine (y el audiovisual en general) comercial actual: el MRI.

Por ello será necesario establecer un marco teórico lo suficientemente amplio, abarcando textos que comprendan teoría del arte, filosofía contemporánea, narrativa (y narrativa audiovisual), discurso informativo y teoría cinematográfica. Este enfoque multidisciplinar es lo que permite a la investigación ir más allá de la pura materialidad del texto y superar el ámbito estrictamente cinematográfico para pasar a hablar de la representación del mundo mediante un determinado tipo de discurso, estipulado en base a unas reglas que relacionamos con el empirismo de la modernidad; y de otro tipo de discursos que subvierten -o no- el tipo de representación anterior, contribuyendo a la idea posmoderna de la incredulidad de los metarrelatos modernos y el fin de la Historia unitaria, progresiva y racional.

\section{Objetivos}

El objetivo principal del artículo es llevar a cabo una aproximación a las películas cuyo hilo argumental y temporal se ve dislocado por la trama, esto es, por la presentación cronológica del mismo, o por la focalización narrativa, para esclarecer si su subversión formal comulga con la filosofía posmoderna. Es decir, si resulta ser una desvelación de la condición de representación de la Historia progresiva y unitaria que la Modernidad había configurado mediante discursos que presentaban un mundo coherente, sin fisuras, unitario, pero articulado según una única perspectiva: la del hombre blanco occidental y heterosexual.

\section{Material y método}

El objeto de estudio lo componen películas que tienen en común la presentación del argumento, de los hechos diegéticos, alterados cronológicamente o presentados desde varios puntos de vista que difieren entre sí. Consideramos posmodernas este tipo de películas por una serie de cuestiones: la fragmentación presente tanto en su estructura temporal y narrativa como en su misma forma (encontramos pantallas partidas, por ejemplo) y en su contenido, moteado de referencias a géneros cinematográficos manidos y a películas concretas... están además protagonizadas por sujetos desarraigados que albergan un malestar incomunicable hacia todo su entorno y hacia sí mismos, y narradas en varias ocasiones desde diferentes puntos de vista que enfocan realidades que cambian en función de la subjetividad del narrador, acoplándose a la idea posmoderna de que la realidad y la Historia unidireccional se ha 
vuelto problemática y sólo se puede representar desde diferentes perspectivas que el relato de la Modernidad invisibilizaba.

Para indagar en el sentido de estas películas, el método utilizado será la lectura de la bibliografía correspondiente, esbozada en la introducción, y el análisis textual que nos permita encontrar el sentido de la película en sí y establecer las relaciones pertinentes con aquello leído.

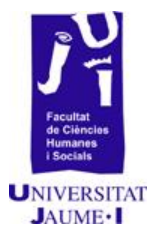

\section{EL cine posclásico en la cuerda floja de la no linealidad. El abismo de lo real frente al empirismo del MRI}

Constituye el punto de partida del presente trabajo una serie de películas cuyo rasgo unificador consiste en la «torsión del argumento por la trama» (Palao, 2007: 180). Su linealidad narrativa se rompe, puesto que los hechos diegéticos no son presentados cronológicamente, sino desordenados o repetidos desde diferentes puntos de vista. Es por eso que el espectador se ve obligado a reordenar las secuencias, a hacerlas encajar y darles sentido, ejerciendo «un trabajo de interpretación espectatorial, sin el cual el texto fílmico no se sostiene» (Palao, 2007: 180).

\section{Películas posclásicas con la trama dislocada, crisis de la Modernidad y empirismo del MRI}

Consideramos que las películas de las que hablamos, se inscriben dentro del Cine Posclásico, por una serie de razones tanto formales como referidas al contenido. Encontramos la huella de la Posmodernidad-que, para bien o para mal, es difícil negar que es la época en la que nos encontramos- en diversas de sus características, algunas de las cuales nombramos a continuación dado que la inscripción de estas películas como posmodernas, en cierto sentido, es lo que nos permite comenzar el razonamiento de este trabajo.

En cuanto a la forma, para empezar queda patente la «obsesión [...] con los fragmentos y las fracturas ${ }^{1}$ en múltiples aspectos. Por ejemplo, en la canadiense The Tracey Fragments (Bruce McDonald, 2007) la pantalla, el plano, estalla en multitud de subplanos, o fragmentos (spleet screen) que presentan diferentes angulaciones, motivos, espacios e incluso desfases temporales, conviviendo y moviéndose dentro del mismo encuadre que supone el plano final y el marco de la pantalla de cine, o televisión, o reproductor multimedia en que se esté visualizando. Otro de los ejemplos de pantalla partida puede observarse en 500 días juntos (500 days of summer, Marc Webb, 2009), donde vemos una secuencia en la

${ }^{1}$ PICÓ, Josep. Proceso a la razón en Debats, no 14, Pág.40. 
que la división del encuadre separa las expectativas del protagonista del presente diegético que sucede en realidad.

Además encontramos también fragmentación en lo que respecta a los puntos de vista, de manera que, como sucede en La mujer del puerto (Arturo Ripstein, 1999), caso en el que profundizaremos más adelante, podemos encontrar un mismo hecho narrado desde los puntos de vista de diferentes personajes: esto es, las focalizaciones varían sobre un mismo presente diegético (que cambia en función de éstas). 0 también, en Crash (Paul Haggis, 2004) o la trilogía del dolor de González Iñárritu, relatos completos que surgen del ensamblaje de diferentes historias que lo acaban conformando, de manera que el argumento se comprende en su totalidad sólo tras haber montado las diferentes tramas, que convergen en determinados momentos de la diégesis cuya teorización y clasificación ha llevado a cabo José Antonio Palao².

Siguiendo con la huella postmoderna en estos films, podemos hacer referencia a la cita o guiños que se hacen hacia el mismo cine en 500 días juntos recordando, por ejemplo, El séptimo sello (Det sjunde inseglet, Ingmar Bergman, 1957) o en Hable con ella (Pedro Almodóvar, 2002), parodiando la tradición del cine mudo.

Pero también en los propios protagonistas de las películas vemos la diferencia de éstos con los héroes del cine clásico. Nos encontramos frecuentemente siguiendo las (anti)peripecias de antihéroes, sujetos desarraigados habitados por un malestar endémico, desencantados de su vida, de sus relaciones, de su entorno... Frecuentemente son personajes desengañados que arrastran «el dolor de una pérdida genérica emparentada, sin duda, con esa herida lacerante que tienen los personajes del melodrama» (Palao, 2007: 180). Es este el caso de Memento (Christopher Nolan, 2000), La deuda (The debt, John Madden, 2011) o incluso The Tracey Fragments.

Pues bien, tanto la quiebra de la linealidad narrativa por esta torsión del argumento por la trama como la fragmentación o la metarreferencialidad de este tipo de películas, las relacionamos, en principio, con el descrédito de la Modernidad y sus valores y presupuestos fracasados, cuya crítica elaborarán los pensadores posmodernos. Intentaremos explicar durante los siguientes párrafos el por qué de dicha relación.

Los pilares de la Modernidad (Razón, Historia y Progreso) dejan ver las contradicciones que conllevan en el siglo XX más claramente que nunca: por citar un par de ejemplos, el progreso científico ha servido en su aplicación destructiva para llevar a cabo la aniquilación humana masiva gracias a la técnica, al tiempo que las consecuencias de la industrialización, cuyo legítimo fin consistía en dominar la naturaleza para aprovecharla mejor, hacen mella en el medioambiente. Ha quedado

\footnotetext{
${ }^{2}$ En Hiperencuadre/Hiperrelato: Apuntes para una narratología del film postclásico. Nuevas tendencias e hibridaciones de los discursos audiovisuales contemporáneos, 2012.
} 
constancia también de que el concepto de Historia, ni es progresivo (cuya muestra más clamorosa para los ciudadanos del siglo XX es la II Guerra Mundial, a no ser que nos acojamos a la idea del devenir de un Espíritu Absoluto hegeliano cuyos motivos son superiores a nuestro entendimiento), ni es universal o unitario. Es importante esta última crítica posmoderna, puesto que la relacionamos con la adopción de múltiples focalizaciones en las películas de las que nos servimos para elaborar esta reflexión. Gianni Vattimo propone al respecto que «la modernidad deja de existir cuando [...] desaparece la posibilidad de seguir hablando de la historia como una entidad unitaria» (Vattimo, 1990: 10) y, como recoge de un escrito breve Walter Benjamin (Tesis sobre la filosofía de la historia, 1938), esto sucede porque esta Historia Universal no es sino «una representación del pasado construida por los grupos y las clases dominantes [que transmite] sólo lo que parece relevante» (Vattimo, 1990: 11), lo que interesa al hombre europeo moderno con poder. Resulta esto un hecho más evidente todavía tras la descolonización desastrosa de aquellos países en los que presuntamente se pretendía inculcar los ideales ilustrados y racionales, pero a los cuales en realidad se negó brutal y sistemáticamente el sapere aude, y que «han vuelto problemática de hecho una historia unitaria» (Vattimo, 1990: 12) al reivindicar su propia historia e identidad. $Y$, en este surgimiento de voces reivindicativas de su diferencia, tiene un papel central el desarrollo de las Tecnologías de la Información y la Comunicación.

Como señala Picó, los grandes relatos modernos que prometían la emancipación humana -entre los cuales destacamos el capitalista y el socialista- han fracasado también en su aplicación, desacreditando los ideales de la Revolución francesa y la crítica marxista revolucionaria. Estamos ante la «incredulidad con respecto a los metarrelatos» modernos teorizada por Lyotard (1987: 3), que implica la pérdida de la Narración de la Historia con un sentido único y completo, que da razón de ser a nuestras vidas. Como recogía Vattimo, la caída de la Razón y el Metarrelato moderno conlleva una explosión de las diferentes «concepciones del mundo» (Vattimo, 1990:13), de microrrelatos. La plasmación de esta idea en las películas de las que partimos es muy notable en ocasiones, como en Crash, o Babel (Alejandro González Iñárritu, 2006), que se articulan a partir de la suma de diversas pequeñas historias acabando por formar la Historia, que no puede ser juzgada ni entendida unilateralmente, pues se nos ha ido desvelando que todo tiene muchas caras que se influyen unas a otras.

Según Palao, frente a la maleabilidad del hipertexto que permite al usuario disfrutar, consumir el texto interminable según la ruta que el usuario desee (poniendo «el ente a disposición del sujeto [en forma de] información concebida como saber sin sujeto" (Palao, 2008: 292), autónoma, con la consiguiente pérdida de responsabilidad del mismo), esta quiebra de la linealidad de la narración, permite mantener «un punto 
oscuro en la economía de la información. Y cerrar una ventana a la información es abrir una puerta a la verdad» (Palao, 2008: 294), porque la información entendida dentro del Paradigma Informativo actual (Palao) se presenta como si no necesitara de la función del sujeto para funcionar, mientras que la verdad es del orden de lo real, y no puede concebirse sin un sujeto al que concierna.

De esta manera, «dar un corte a la continuidad del discurso remite al enunciatario a su responsabilidad subjetiva en el goce de la consistencia del mundo» (Palao, 2008: 294). Es decir: las películas que alteran el orden de presentación del argumento, obligan al sujeto a hacerse cargo de la reordenación del argumento, de manera que éste no tiene sentido sin su función de sujetos que suturen (Oudart) conscientemente. Si asimilamos las películas de Cine Clásico (Bordwell acota la producción de éste en el Hollywood de entre 1930 con la llegada del cine sonoro y 1960 con los nuevos cines) cuya base fundamental es el Modo de Representación Institucional (Burch) a los metarrelatos modernos que presentaban un mundo de sentido pleno por sí mismos, en un primer momento se podría pensar que se ha dejado de creer en aquellos grandes relatos que se sostenían sin que los espectadores, una vez interiorizado profundamente el funcionamiento del MRI, fueran conscientes de su función de sujetos suturadores, para pasar a activar la conciencia del sujeto, avisándole de que es él el que otorga la consistencia al relato, ya que su función es mucho más evidente cuando un supuesto presente diegético se presenta desordenado temporalmente. La responsabilidad de la reestructuración de ese presente con el fin de que adquiera sentido es mucho más patente, puesto que las unidades que hay que hacer concordar son generalmente sintagmas mucho mayores que las uniones mínimas de planos (cuyas relaciones tenemos, en general, profundamente arraigadas), y llevan en su seno cientos de éstos cuya yuxtaposición no ha llamado la atención del sujeto antes. Consideramos esto consecuencia de que (en palabras de Bordwell), en el MRI, que presupone un espacio de la representación homogéneo con un fuera de campo también homogéneo y estable, susceptible siempre de ser representado, se da un «desplazamiento de la percepción del espacio desde el plano a la intersección de los mismos, es decir, declaración de la insuficiencia figurativa del plano y, por otra parte, imperceptibilidad de tal operación» (Palao, 2004: 246).

Posteriormente incidiremos en la importancia de que al sujeto le impacte la necesidad de recomponer él mismo el relato.

El hecho de dislocar el argumento por la trama, visto así podría considerarse una especie de subversión, puesto que estaría desnaturalizando el metarrelato/MRI, dejando ver que no es algo que se sostenga por sí solo, que los hechos no se engarzan solos, sino que desvelaría su condición de lenguaje articulado que necesita ser leído y formulado en base a unas reglas. 
Debemos aclarar en este punto que, si relacionamos el MRI con la Modernidad, y las películas que lo subvierten con la Postmodernidad, es porque consideramos que el MRI se basa en un cierto empirismo-como argumentaremos seguidamente- y confirma un espacio homogéneo, estable y representable que se corresponde con el universo cartesiano, plenamente moderno.

MRI y Cine Clásico tomado como el mejor ejemplo de éste, funcionan según unas reglas que no deben infringirse -siendo el Código Hays su máxima expresión-, de manera que hay un cierto grado de previsibilidad en su lógica interna, y una seguridad de que «en el final debe advenir un saber absoluto, es decir, idealmente, no debe quedar resquicio para la duda respecto a ninguno de los hilos que puedan conformar la trama » (Palao, 2008: 293). Tales reglas determinan la utilización del dispositivo cinematográfico en sí, como sucede con las leyes de los ejes, las angulaciones no aberrantes, el enfoque... contribuyendo a resaltar siempre aquello que interesa de la narración, convirtiendo la cámara en un observador ideal y muy discreto. $Y$ evidentemente, también la forma de narrar, dando lugar a "las características modélicas del relato clásico, con las que consigue este objetivo de prender al espectador sin defraudar sus expectativas» (Palao, 2008: 293), que Bordwell describe y Palao recoge y comenta. Las que más nos conciernen son que «el personaje es el medio causal para el desarrollo de la acción, que toda acción se orienta hacia un objetivo reconocible y [...] calculable, y la indiscutible linealidad, que implica la necesidad de un avance temporal y narrativo tras cada secuencia» (Palao, 2008: 293). De este modo, «la omnisciencia narrativa se resuelve en omnipresencia escópica, produciendo la total adecuación mirada-relato que connota la plena disponibilidad del mundo-imagen para el sujeto en forma de la identificación del objeto con el saber» (Palao, 2004: 251). Todo esto se lleva a cabo mediante el borrado de las huellas de enunciación, de manera que el discurso disimula estar enunciado por alguien y sostenido por el sujeto que lo ve, en pro de una enunciación transparente (nótese la concordancia con la idea de universalidad omnipotente del gran relato moderno).

La repercusión de esta manera de narrar es que, cuando el espectador se sienta ante una película perteneciente al MRI o Cine Clásico, sabe perfectamente que ningún objeto que aparezca es sin causa, que toda acción tendrá una consecuencia y será motivada... en definitiva, que nada está o es porque sí, a nada le falta el sentido, pues, como hemos dicho, el final del relato se cerrará sin que al sujeto espectador se le escape nada: la verdad que enuncia este relato cerrado, será perfectamente entendible para él (de ahí el funcionamiento del MRI y aún más del Cine Clásico como un metarrelato moderno, cuya acción avanza en cada secuencia -al modo de Historia progresiva- dirigiéndose a la resolución de sus conflictos).

En este sentido nos referimos a que, utilizando la razón empírica, siguiendo las pautas de lectura, pensando en las reglas, en las causas y las 
consecuencias, en la naturaleza de los hechos, y confiando en el progreso indefinido que llevará siempre a «la anulación de su causa [la del relato], a convertir la potencia (sujeto, menos objeto) en acto pleno» (Palao, 2008: 293), el sujeto adquiere el saber encerrado en ese discurso (la obtención de este saber absoluto es, de hecho, una de las características del Cine Clásico). En el MRI, pero sobre todo en el Cine Clásico, nada escapa a la experiencia de la percepción. Lo no visible, lo no cognoscible, lo que la Razón empírica no puede procesar, queda fuera de cualquier intento de representación en estos discursos.

\section{Aparente ruptura del Cine Posclásico con el MRI en base a la no- linealidad}

Recapitulamos: hemos defendido que el MRI, modo de representación hegemónico en el discurso audiovisual comercial contemporáneo, funciona según un conjunto de reglas cuya decodificación hemos asimilado al funcionamiento de la razón empírica, y que el resultado de sus discursos cerrados enunciaba una verdad que, como los metarrelatos modernos, presentaba un mundo pleno de sentido.

El hecho de que el MRI se base en la enunciación transparente nos hace pensar que contribuye a algo que, según Michel Foucault enuncia en El orden del discurso, ha sido una preocupación constante en el pensamiento occidental: velar «para que en el discurso haya el menor espacio posible entre el pensamiento y el habla» (Foucault, 1973: 39). Este esfuerzo sería realizado en función de ocultar cierto temor a lo que hay detrás del discurso, "contra esos acontecimientos, contra esa masa de cosas dichas (...) contra todo lo que puede haber allí de violento, de discontinuo, de batallador, y también de desorden y de peligroso, contra ese gran murmullo incesante $y$ desordenado de discurso" (Foucault, 1973: 42). Y esto casa muy bien con la preocupación por que el discurso lo sea todo, sea la transferencia inmediata del mundo -que dentro del Paradigma Informativo, según Palao, tomará a la idea de la información como saber autooperativo, discurso que se sostiene solo-, rehuyendo el noúmeno, la cosa en sí, el vacío de lo real (que describiremos más adelante), lo innombrable, ya no en su representación, que es por definición imposible, sino en su existencia al ocultar este más allá del discurso.

Foucault sostiene (1973: 43) que para borrar este temor, precisamente lo que se necesita es

no resolver el discurso en un juego de significaciones previas, no imaginarse que el mundo vuelve hacia nosotros una cara legible que no tendríamos más que descifrar; él no es cómplice de nuestro conocimiento; no hay providencia prediscursiva que le disponga a nuestro favor. Es necesario concebir el discurso como una violencia que hacemos a las cosas, en todo caso como una práctica que les imponemos; es en esta práctica donde los acontecimientos del discurso encuentran el principio de su regularidad. 
Lo que nos interesa en definitiva de estas citas, es que reconocen que el mundo no se corresponde con su representación ni está dispuesto para ella motu propio, para dejarnos ver su sentido sin fisuras, que es algo que la naturalización del MRI oculta mediante el borrado de las huellas de la enunciación.

Volvamos ahora a las películas de trama no lineal. Al presentar secuencias temporales de una misma diégesis desordenadas en función al presente diegético en que supuestamente están inscritas, inevitablemente están rompiendo con el raccord espacio-temporal, que constituye uno de los pilares de orientación del MRI. A su vez, hacen ver al espectador que él, en su función de sujeto suturador del discurso, es quien le otorga sentido y lo sostiene, poniendo en cuestión el sentido inmanente a los Metarrelatos cuya enunciación era transparente y parecían sostenerse por sí solos; es decir, dejan ver que hay alguien detrás del discurso que lo está enunciando de cierta manera y obligando a seguir una ruta de lectura y a hacer un esfuerzo, no sólo de decodificación, sino de reconstrucción y otorgación de sentido. Y esto lo consiguen distanciándose del Hipertexto, pues la ruta de lectura no es libre, y de forma aparentemente diferente del MRI, pues lo desafían en la torsión del argumento por la trama y en su multiplicidad de focalizaciones que difieren de la omnisciencia discreta de aquel observador ideal, entre otras cosas.

Se podría decir, desde este punto de vista, que por todo ello estos filmes están rompiendo con la Modernidad (llevada al ámbito cinematográfico) y con el uso tradicional que de la razón empírica se había hecho en base a las reglas del MRI, pues aplicándolas tal cual las conocíamos, no entendemos nada. Aquí es de donde partimos al tener la sensación de que estas películas, además de asimilar la Posmodernidad en la forma, la asimilan también de manera ideológica al poner en duda la Razón empírica, la univocidad de las interpretaciones del mundo por parte de los personajes, en suma la claridad propia de la llustración.

Pero esta es sólo una premisa inicial a partir de la cual nuestras consideraciones van a variar y desarrollarse.

\section{Reconstrucción del MRI gracias a la reestructuración del relato y recuperación del sentido pleno}

Ante estas tramas, pues, al espectador no le queda otra más que hacerse cargo de su reinterpretación, de la reordenación del discurso desde su posición subjetiva. Todo su esfuerzo se centra en volver a reconstruir el sentido del relato para recobrar la certeza en la representación de la que habla Heidegger, desestabilizada por la ruptura de la linealidad, que ha hecho quebrar en consecuencia la homogeneidad espacial y temporal. 
Pero, en la mayoría de películas que estamos tratando, una vez el sujeto espectador ha reconstruido el discurso que se presentaba alterado, como venimos apuntando, el MRI sale fortalecido de su puesta a prueba. Porque el sujeto ha conseguido, mediante el engarce consciente de las piezas, mediante la reconstrucción de las puzzle films (Warren Buckland: 2009), reedificar ese mundo sobre la ley del raccord. Porque a través del reordenamiento mediante el uso la razón empírica que restaura el MRI atendiendo a la recomposición de sus reglas, que reestructuradas vuelven a encajar, accedemos al relato que de nuevo, tiene correspondencia sin resto con el mundo. De este modo, la crítica a la Modernidad no es tal, pues sólo en apariencia se ha desconfiado del metarrelato, de la falta de sentido, de la omnipotencia de la Razón empírica, si al terminar de atar cabos todo vuelve a su sitio sin fisura alguna más allá de la forma cicatrizada. La desconfianza inicial del sujeto queda sanada por el esfuerzo mental recompensado.

Este supuesto sería el de películas como 500 días juntos, cuya sensación final no implica falta ni problemática alguna, pese a presentarse como una doble deconstrucción: del MRI y de la comedia romántica tradicional. Es decir, consideramos las películas con argumento dislocado pero posibilidad de reconstrucción final sin fisura, un ejercicio formal, estético, que las hace aparentemente subversivas y quizás más atractivas comercialmente (recordemos que hablamos mayormente de películas generadas por la industria hollywoodiense) por diferenciarse del resto.

Esto no obstante, no pensamos que todo intento de subvertir el MRI para poner en evidencia su falta de consistencia inmanente respecto del mundo, mediante la no linealidad, sea en balde. Primero, porque no consideramos legítimo que se utilice la estructura del metarrelato moderno o las leyes del raccord y el MRI como se ha venido haciendo en el Cine Clásico para desvelar la falta de consistencia del mismo, la potencia limitada de la razón empírica. Da la sensación de que esto sería una suerte de hipocresía formal. Nos amparamos para realizar esta consideración, por ejemplo, en el estilo utilizado por Nietzsche, basado en el aforismo, en la metáfora, e incluso en la expresión poética (Hottois, 1997: 242), puesto que

\footnotetext{
se compenetra bien con la idea de que la realidad es plurívoca [...] [y] el lenguaje unívoco del concepto lógico y científico no es adecuado para describirla; únicamente un lenguaje metafórico, más connotativo que denotativo y que exija una interpretación creadora, es capaz de expresar el mundo.
}

Por otro lado, no en todos los filmes analizados hay un final que transmita paz al sujeto que se ha encargado de dotarlo de sentido. En este MRI cicatrizado puede haber agujeros negros, vacíos insalvables, tanto empíricamente, atendiendo a reglas narrativas, como a un nivel de 
contenido más intangible. Es en esta falta de paz, relato inacabado, inconsistente, con fisuras que provocan cierto malestar, donde vemos la posibilidad de desvelar la falta de inconsistencia del modo de Representación Institucional, como detallaremos a continuación.

4. Lo real como causa del malestar derivado de la crisis de los metarrelatos modernos aplicados al MRI

Para definir la angustia, la falta de certeza, el vacío de sentido que dejan algunas de las películas cuyo argumento es torcido por la trama, apelaremos al concepto de lo real utilizando como ejemplos de su aplicación The Tracey Fragments y La mujer del puerto.

De todas las acepciones posibles de lo real, nos aproximaremos a la que utiliza la teoría psicoanalítica lacaniana, aludiendo después a la forma en que hace suyo el concepto González Requena, contraponiéndolo al de realidad.

Desde el psicoanálisis, lo real se entiende como aquello que 10 simbólico -el lenguaje, la cultura- no puede cubrir del todo, de manera que queda como innombrable, inaccesible, incognoscible. Cuando el viviente llega al mundo y le envuelve la cultura, el lenguaje, puesto que está condenado a representarse por él y experimentar una pérdida irreversible ${ }^{3}$, se convierte en sujeto que necesita recuperar ese goce perdido, con lo cual estará perpetuamente en falta. «El sujeto deberá suturar la falta en el Otro, los impasses del discurso» (Palao, 1993: 7), para reprimir la pulsión que ha aparecido tras la castración del instinto dada al entrar en la cultura. Por todo ello, el sujeto se ofrecerá al lenguaje como Otro para suturar esta falta de sentido.

De esta manera, lo real es aquello a lo que no podemos acceder y sin embargo sale a nuestro encuentro -recordándonos al punctum de Barthes-, "lo que no anda, lo que se pone en cruz ante este convoy, más aún, lo que no deja de repetirse para entorpecer esa marcha» (Palao, 2004: 79). Aquello, volviendo momentáneamente a la Modernidad a través de Kant, que recuerda al noúmeno, pues «encontrándose en el seno del saber como SU núcleo insoslayable, no se deja absorber por él» (Palao, 2004: 80).

González Requena, por su parte, retoma este concepto para contraponerlo al de realidad: mientras que "lo real no es transparente sino esencialmente opaco» (1989 a: 16) y necesita del lenguaje para hacerse inteligible, "la realidad sería lo que en el mundo hay de comunicable» (1989 a: 17). El autor entiende así, que hay una diferencia

\footnotetext{
${ }^{3}$ Según recoge Palao, esta imposibilidad viene dada porque ya se considere el significante, ya el significado, la lengua no comporta ni ideas ni sonidos preexistentes al sistema lingüístico, sino solamente diferencias conceptuales y diferencias fónicas resultantes de ese sistema [...] y ello implica [...] que, desde la lengua, no hay posibilidad de constituir un ámbito total y único, pues definir algo por su diferencia implica excluirlo como elemento del conjunto que lo define; y segundo, la imposibilidad de erradicar el sinsentido sin parcialidad. (Palao, 2004: 51).
} 
esencial entre uno y otro, y es el resultado de la mediación del lenguaje (de lo simbólico), la dación de forma a lo real, convirtiéndolo en realidad. Partiremos de que esta mediación no puede hacerse cargo, in-formar lo real, completamente -pues se tornaría realidad, fenómeno-, y de ese horror ante el vacío viene la obsesión por la transparencia enunciativa de la que antes hablábamos, el hacer ver que el discurso es todo, la "demanda de un mundo transparente [...] [que] contiene, en último extremo, una fantasía de omnipotencia [...] y, a la vez, complementariamente, un rechazo paranoide de lo real» (González Requena, 1989 b: 73). De este modo, mediante esta pretendida enunciación transparente (en el caso que nos ocupa referida el MRI) lo que se está ocultando a conciencia (pues cuesta su esfuerzo este trabajo de naturalización), es que "la verdad sólo puede decirse a medias» (Palao, 1993: 8), dada la imposibilidad de llegar al noúmeno, a la esencia, que generará ese malestar, ese temor. De esto se puede llegar a pensar, paradójicamente, que «un enunciado verdadero no sería, así, el que se ajusta a la realidad de los hechos o de las cosas, sino el que apunta al agujero de lo real» (Palao, 1993: 8).

Así pues, partiendo de estos conceptos de lo real, lo utilizaremos aquí como malestar, angustia, herida, vacíos de sentido, falta de paz, de sosiego, de estabilidad, incomprensión a la que no se puede dar forma, imposible de aplacar mediante la palabra y mediante la razón empírica.

Lo que estamos planteando, de alguna manera, es que en algunas de estas películas posclásicas no lineales, al acabar se niega «la creencia en la absoluta certidumbre jurídica en un mundo escénicamente pleno, tras la reparación homeostática que la trama realiza sobre el mundo" (Palao, 2007: 134). Pongamos algún ejemplo para concretar la teoría sobre la materialidad de alguna película.

The Tracey Fragments, podría parecer en principio el simple mosaico de un argumento banal: la aspereza de una adolescencia difícil en un entorno que es (o es percibido) hostil. Pero conforme avanza y termina el relato, nos damos cuenta de que nada ha quedado cerrado. Lo único que se ha planteado han sido conflictos que no han quedado resueltos (rasgo que se nos antoja bastante posmoderno), tras los patéticos intentos de la protagonista por reaccionar ante ellos. Hacia ella se dirige la hostilidad infundada y caprichosa propia del acoso escolar, y la amargura de sus padres, que parecen conllevar con una especie de desquicio que irá en aumento cuando Sonny -que actúa como un perro, supuestamente bajo los efectos de la hipnosis de su hermana- desaparezca. Esto sucederá mientras ella se acuesta con un chico nuevo, lánguido, que parece ser su única ilusión, y el cual la echará literalmente del coche sin miramientos tras -suponemos- desvirgarla fríamente. En su intento de salir a buscar a Sonny, sufrirá entre otras desventuras un intento de violación, así como el encuentro con personajes inquietantes, ocasionales, cuya actitud nos 
punza, por algún motivo, como el hombre que no para de reír en el autobús o una mujer que desespera porque le han robado dinero, dice.

Cuando la película acabe, no sabremos qué ha pasado con Sonny, o qué pretende realmente un tal Lance que dice querer ayudar a Tracey. No es gratuito el estallido del plano en pedazos, ni la no linealidad. Va en consonancia con esta incertidumbre detrás de cada personaje, con ese incluso desconfiar inicial de la percepción de aquél que nos cuenta la historia -aunque al avanzar ésta entenderemos que poco importa su verosimilitud. Si algo queda patente, es el problema de incomunicación que resalta en las conversaciones de Tracey con su psiquiatra (cuyo atuendo recuerda al límite difuso entre representación y disfraz del que habla Barthes en El tercer sentido), que no conducen a ningún lugar por más que la protagonista intente poner de su parte. La angustia que queda tras haber finalizado la película, la desesperanza que se desprende, es el producto de todo aquello que a la protagonista -y al espectador- afecta, pero no sabe describir ni resolver, por más palabras que dirija a cámara. $Y$ no es sólo tristeza, aunque ésta forme parte de su sensación, pues de la tristeza no es tan difícil encontrar la causa. Es un malestar más difuso, más neblinoso, más inaprensible y más inexpresable con claridad.

En La mujer del puerto, se nos presenta el mismo argumento repetido tres veces, variando la focalización en cada una de ellas, de manera que nos llega la percepción de un mismo presente diegético por parte del marinero Marro, la joven prostituta Perla y la madre de ésta, Tomasa. El marinero y Perla inician una relación sexual y amorosa que desembocará en un embarazo de ella. Poco a poco sabremos que desconocían ser hermanos (dado que Marro huyó tras asesinar a su padre cuando era un niño) adquiriendo progresivamente los detalles al ir cambiando la focalización. Los tres protagonistas mantienen una relación tortuosa entre ellos que desencadena repentinos episodios de tirones de pelo, empujones e insultos seguidos de lamentaciones por la incomprensión del resto o la dureza de la vida, o súbitas declaraciones compungidas del amor que se tienen. Tras quedar Perla encinta, asistimos a la diferencia más patente entre la focalización de Perla y Tomasa: según la narración de la primera, su madre le saca al niño del vientre desoyendo sus gritos de horror, con el alambre resultante de desvencijar una percha. Pero cuando la historia se nos presenta desde Tomasa, oímos a Perla suplicar que la ayude a abortar tan fuerte como antes había chillado resistiéndose a la intervención de su madre. Cuando se agote esta última focalización, no sabremos qué sucedió en realidad. Porque no es relativa la realidad consensuada entre las tres visiones, más allá de las características físicas del entorno y los hechos en su radicalidad, como la relación entre Perla y Marro o el embarazo de la joven. Pero cambian tanto las perspectivas, que los hechos se ven sustancialmente modificados. Son un mismo qué pero tan alterado por el cómo que no podemos hablar de realidad intersubjetiva. La subjetividad individual modifica la ficción. Quedamos lejos, de este modo, del relato cerrado que 
presenta un mundo estable. Y lo mismo da que las leyes del raccord se hayan respetado intrasecuencialmente -si bien hay saltos temporales en la parte de Tomasa-, puesto que las visiones se contradicen y se rompe la lógica de un relato (MRI). Pero así escapa la narración del relato unitario, unidireccional y progresivo, rescatando parte de esa verdad tan cercana a lo indescifrable de lo real.

No sólo en la incertidumbre de no saber quién tiene razón, por así decirlo, queda patente lo real en esta película. Es aquí algo adherido a la humedad del ambiente, a las paredes desconchadas, a las palanganas con agua amarillenta, a la ligereza con la que los personajes hablan de temas tan crudos, a la obsesión con la que se agarran a trastos como la pecera del Eneas o la lámpara de la mesita de noche. Algo inherente a los lazos casi instintivos que los unen (constantemente hablan de la carne para hacer referencia a éstos), a no tener nada más que recuerdos de supuestos tiempos mejores que el salitre ha vuelto sarrosos. Si hay un objeto diegético que parece remitir simbólicamente a lo real, lo innombrable, lo incognoscible, es la caja que entierra Tomasa en un jarrón con flores, y que supuestamente guarda el feto engendrado por Perla y Marro - del que no vemos más que la sangre en la cama y en Perla, tras el aborto. Esta caja encierra el hijo del pecado, de lo prohibido, del incesto, de la preponderancia de la satisfacción del deseo ante las leyes morales, pero también de la ignorancia de sus progenitores, de la ocultación de su condición de hermanos, del tabú. Y es algo arrancado de las propias entrañas de una mujer, algo casi esencial (noumenal), algo que nunca se sabrá cómo fue y de lo que dolerá hablar por siempre más, a lo que siempre habrá miedo a acercarse. Algo cuya facultad de infundir horror en los sujetos ha propiciado ese intento de extraerlo y enterrarlo, de arrancarlo de la vida, literalmente.

Pese a que somos conscientes de la ambigüedad resultante de la aplicación de lo real al relato cinematográfico, defendemos que estamos reclamando un concepto de por sí indefinible, puesto que existe por su indefinición, por consistir en un vacío, en ser indecible. Es más, apostamos por que, si se quiere sacar a la luz con el fin de desvelar la inconsistencia del MRI, debe hacerse sutilmente. Debe ser algo que se diga sin decirse, que se sugiera, que emerja como por sí mismo atacando al espectador, contagiándolo de la angustia de no poderse hacer cargo de él. Porque recordamos que la verdad sólo se puede decir a medias. No podemos hablar claramente de algo de lo que desvelamos precisamente que no sabemos cómo hablar, como no podemos utilizar la estructura del metarrelato moderno para criticar su inconsistencia. De ahí que valoremos la angustia, el desasosiego diluido impregnando relatos como The Tracey Fragments o La mujer del puerto.

Se podrá objetar que tanto las desventuras de Tracey como la podredumbre en la que viven los protagonistas mejicanos pueden hallarse en películas que respetan la linealidad. Recordamos entonces 
que la alteración del argumento por la trama la considerábamos legítima si sacaba a relucir malestar como el que hemos intentado definir, puesto que supone una subversión de la forma y lo que ésta connota acorde a la desvelación de la inoperancia de la razón empírica como mecanismo para entender el MRI -y con él, el relato correspondiente y la verdad que pretende enunciar.

Por eso mismo, hemos tenido que dejar fuera del corpus de este trabajo películas que sin embargo, se corresponden con la sugerencia de lo real, del vacío, de lo que se escapa al lenguaje -convirtiéndose en un reflejo parcial del aura teorizada por Walter Benjamin o del sentido obtuso de Roland Barthes- por su modo de representación, bien completamente lineal, insertado en el MRI, o bien del todo ajeno a él. Nos referimos a dos películas en concreto: Tren de sombras (José Luis Guerín, 1997) y La habitación verde (La chambre verte, François Truffaut, 1978). La primera de ellas se correspondería con el aura que rodea a las fotografías y el material fílmico antiguo, pero desvelando al final la condición de falsedad del mismo. La segunda hace referencia por completo al intento de apresar mediante la representación fotográfica gracias a la huella del referente real- y los objetos personales de las personas fallecidas, su espíritu, su presencia próxima, de velar el vacío y el dolor, la pérdida. Pero, tras haber acotado este trabajo al estudio de películas no lineales, como decimos, ambos filmes quedan fuera de su alcance, más allá de esta mención.

Podríamos, si tuviéramos espacio, ir desmenuzando otros films que servirían también de ejemplo para lo que hemos expresado, como Ciudad de Dios (Ciudade de Deus, Fernando Meirelles, Kátia Lund, 2002) o Expiación, más allá de la pasión (Atonement, Christopher Hampton, 2007), pero no disponemos del espacio suficiente como para entrar detalladamente en ellos, y debemos proseguir con el hilo de nuestro trabajo, confiando en que dos escuetos ejemplos hayan sido suficiente para comprender lo que pretendemos expresar.

Las películas que hemos nombrado hasta ahora -dejando de lado estos dos últimos ejemplos-, presentan una deconstucción del MRI que, en mayor o menor medida, puede ser reconstruido formalmente mediante el esfuerzo de sutura espectatorial, quedando al acabar éste un relato más o menos inteligible, cohesionado pese a su subversión, a nivel formal, si bien aflora lo real en la falta de respuestas totales, en la inseguridad final, como venimos diciendo.

Pero encontramos en el cine de David Lynch -concretamente en la trilogía de la carretera (Palao), que abarca Lost Highway (1997), The Straight Story (1999) y Mulholland Drive (2001)- más allá de lo que venimos comentando, una manera de subvertir el MRI desde la pura forma. Dicha subversión ha sido teorizada por José Antonio Palao, y aquí únicamente daremos unas pinceladas por su pertinencia respecto al tema 
que abordamos. Desde la violación de la ley del raccord, Lynch lleva a cabo una "reflexión sobre la connaturalidad de la trama con la imagen del mundo» (Palao, 2008: 297), el resultado de la cual es un MRI irreconstruible, ahora sí, incapaz de entenderse ni siquiera tras ser repensado, puesto que combina universos paralelos, personajes que ostentan identidades diferentes y cuyo deseo subjetivo altera la diégesis, interviniendo en los hechos, en la realidad. De esta manera, «el espectador contemporáneo [ante la apariencia inicial de thriller] espera una lógica que proyecte el orden a posteriori sobre la trama, [puesto que] el estilo clásico cinematográfico es el espacio discursivo de esta estabilidad ontológica» (Palao, 2008: 298-299). Pero acaba encontrándose que estas películas están habitadas por el deseo, por la lógica interna de sus propios personajes, como sucede con Betty en Mulholland Drive.

Lynch consigue aunar, pues, la subversión formal irreconciliable con el MRI y el metarrelato moderno y la atmósfera inquietante salpicada de personajes siniestros que nos provocan la inquietud de la que hablábamos antes, con ese cierto tinte onírico que le caracteriza.

\section{Desvelación de la inconsistencia del MRI en su reciprocidad con el mundo}

Por todo lo que venimos explicando, en algunas de las películas que forman parte de este tipo de cine, queda al descubierto la inconsistencia del MRI en su reciprocidad con el mundo. Nos referimos a que, al quedar en evidencia la enunciación, el hecho de que el espectador se da cuenta de que hay alguien tirando y aflojando de la cuerda que les permite acceder al saber del relato, se ve de forma clara que el MRI no es una transfusión de la realidad sin mediación alguna, que los relatos no son desinteresados. Hay esfuerzo y trabajo de naturalización, de ficcionalización, detrás de este modo de representación. Y, como vemos explícitamente en Lynch, al haber montaje, el raccord no es natural y el espectador es susceptible de ser engañado mediante su uso.

Este tipo de desvelación no es baladí, si tenemos en cuenta que el cine modeliza el mundo ${ }^{4}$. Es decir, que ante la fruición actual por transgredir horizontes en lo que respecta a conseguir la docilidad del mundo, su apresamiento en forma de representación, ante la necesidad de cada vez ver más, verlo todo, e incluso ante la idea de que lo que no sea susceptible de verse, de ser representado, no exista, el Modo de Representación Institucional es la manera en que se nos presenta el mundo para que lo entendamos. No tenemos más que pensar en los informativos televisivos actuales. Cuando no hay imágenes de un hecho considerado noticioso, se recrea. Ya sea mediante infografía (como

\footnotetext{
${ }^{4}$ Esto es, mediante la posibilidad de crear un efecto de realidad a partir de un efecto de real (Palao), el cine es capaz de construir una (falsa) verdad verosímil, naturalizada, a través del montaje.
} 
sucede en la televisión taiwanesa NMA) o animación (en el caso español, por ejemplo en los informativos de LaSexta), la cuestión es que se procede a crear un pequeño corto de ficción apoyado por la voz del narrador/presentador del informativo. Podríamos nombrar también toda una serie de programas televisivos que ficcionalizan y espectacularizan supuestas vidas cotidianas de las que surgen relatos profundamente escatológicos sobre, por ejemplo, la dificultad de criar a los hijos, el día a día de los adolescentes problemáticos o la experiencia de la maternidad a edades tempranas. Mediante estos informativos y reality shows observamos el presupuesto de que no solamente todo lo que hay se puede ver (pensamos en cámaras en cada estancia de la casa de Gran Hermano o la mostración del plató en programas como Sálvame), sino que lo que se ve es todo lo que hay. El mundo a disposición de un espectador estático, sin grieta alguna.

Parte de la responsabilidad la tiene el propio carácter fagocitador y omniinclusivo del medio televisivo, que hace desaparecer el contracampo que habita el espectador convirtiéndolo, como en los programas nombrados, en potencialmente encuadrable.

Partiendo pues de que mediante esta ficcionalización del mundo (y la naturalización de la ficción) accedemos a la realidad que los medios de comunicación presentan, la puesta en evidencia de los mecanismos del MRI, de su artificialidad, supone ya no la sospecha latente de la manipulación mediante el montaje, sino su falta de reciprocidad con el mundo. El surgimiento de aquello que escapa a la representación. La desvelación de que desde el MRI no se puede acceder a un mundo de sentido pleno que esté esperando ser representado (en la línea de lo que Foucault reivindicaba en relación a los textos). La certeza en la representación, como veníamos apuntando, se tambalea.

$Y$, tirando del hilo: si el discurso cinematográfico con el MRI a la cabeza es la representación que goza de más verosimilitud entre audiencia/espectadores/usuarios, al quedar al descubierto su engaño, queda con él en entredicho la noción misma del mundo a la cual accedemos por mediación de este discurso. Lo cual, desde la posición que defendemos aquí, no es ningún drama demasiado escandaloso, si recordamos que siempre quedará el resto de lo real por representar, por comprender, por designar, y que la propia condición de representación de lo que se entiende por Historia Universal, por mundo con sentido, es lo que la Posmodernidad visibiliza, desvela.

Si, como recoge Vattimo (1990: 15), en la Posmodernidad en la que nos encontramos, «intensificar las posibilidades de información acerca de la realidad en sus más variados aspectos hace siempre menos concebible la idea misma de una realidad", no resulta sorprendente que la realidad vista unitariamente, (re)presentada por los medios de comunicación como sentido pleno del mundo, recordando al metarrelato, quede resquebrajada tras la subversión del MRI. De hecho, atendiendo a la crisis de la Modernidad y a la desconfianza de los puntos de vista únicos y la 
Historia Universal unitaria que resulta ser aquella que el mundo occidental con poder ha deseado plasmar, «si con la multiplicación de las imágenes del mundo perdemos el "sentido de la realidad", como se dice, no es en fin de cuentas una gran pérdida» (Vattimo, 1990: 17).

Bien al contrario, se trata de acabar de dinamitar ese punto de vista único, esa hegemonía del relato unitario que, haciéndonos creer que tenemos el mundo a nuestra disposición, precisamente nos impide hacernos cargo de lo que no podemos conocer, presentándose como dador de todo lo cognoscible. $Y$, teniendo en cuenta que los discursos hegemónicos tienen intereses detrás, presentan una visión del mundo que les conviene y justifica, esta alienación del sujeto espectador, lector, es potencialmente peligrosa. De ahí la legitimidad de la contribución del discurso cinematográfico a esta ruptura con lo que se ha demostrado instrumento de dominación. De ahí la validez de los discursos que, a costa de su fragmentación, dan lugar a cierta subjetivación del mundo y posibilitan engarzar múltiples perspectivas identificadas (microrrelatos) de las cuales surgirá la visión final (que incluso así no será capaz de cubrir del todo aquello de lo que hable), la realidad intersubjetiva.

Pero la practicidad de la desvelación de la reciprocidad del MRI con el mundo consiste en hacerla ver a los espectadores y no a los teóricos del cine, pues éstos conocen la naturaleza del lenguaje cinematográfico. La utilidad de la subversión reside en contribuir a que los ciudadanos que cada día se exponen a los discursos de las instancias de poder a través de los medios de comunicación y las industrias culturales sean conscientes de los intereses que hay detrás de la ficcionalización de la realidad y cuestionen aquello que se les presenta como realidad objetiva.

Por este motivo, la desvelación de la que hablamos debe ser algo inesperado, una sorpresa, puesto que las expectativas que se manejan ante un discurso tienen mucho que decir al respecto. Si nos sentamos frente a una película que sabemos de entrada que difiere de los modelos de representación clásicos, que para el público resulta rara-como puede suceder, por ejemplo, con El año pasado en Marienbad (L'année derniére à Marienbad, Alain Resnais, 1960)- difícilmente lo que se vea podrá hacer caer ninguna venda de la mirada de nadie, porque la forma ya nos predispone a aceptar distorsiones, no nos chocan los hechos diegéticos no justificados ni la violación del raccord, ni acabar el relato sin entenderlo del todo.

Por eso, no se trata de criminalizar el MRI, sino de hacer ver que no es el portador de la verdad ni omnipotente por sí mismo y que se pueden decir otras cosas mediante otro tipo de narración. Para que la deconstrucción sorprenda, debe darse en películas que parezca que van a seguir una enunciación transparente para luego dejar constancia de la instancia enunciadora, para romper las reglas que se han respetado en un principio. Se podría así subvertir también cualquier otro modo de representación y no sólo el $\mathrm{MRI}$, simplemente jugando con las reglas 
propias de cada cual, con lo que se espera. Si aquí nos centramos en el MRI es porque, por un lado, consideramos que su puesta en evidencia dada su proyección en los medios de comunicación- tiene consecuencias más allá del ámbito cinematográfico, y por otro lado a él pertenecen la mayoría películas a las cuales nos hemos aproximado.

Encontramos en un artículo del profesor Francisco Javier Gómez Tarín 2000: 14) referido a Tren de Sombras (José Luis Guerín, 1997), palabras muy próximas a lo que pretendemos decir en relación a la deconstrucción del MRI. Gómez Tarín la encara al desmantelamiento de la homogeneidad de los productos considerados comerciales por las industrias culturales, que deciden y definen "los gustos del público, al que impone las direcciones de sentido, las lecturas y, cómo no, las interpretaciones, generando un imaginario que le hace acomodaticio a la búsqueda del pasar el tiempo y ya no del goce" y dejan al margen obras como Tren de Sombras en las que, en consonancia con algunos rasgos de las películas que venimos citando, "no hay imposición de sentido, no hay transmisión de imaginario, pero sí hay reflexión, lucidez y, sobre todo, resistencia ante una mercantilización que nos hace dudar del futuro de la representación cinematográfica» (Gómez Tarín, 2000: 14).

Utilizaremos sus palabras, con toda probabilidad más esclarecedoras que las nuestras, para dejar constancia de la importancia de la subversión desde la representación cinematográfica, desde el ámbito de la cultura, con el fin de desvelar mecanismos de ejercicio del poder velados tras la naturalización de aquello que es un constructo cultural, como sucede con el MRI y como sucedía con la noción de Historia Universal.

Gómez Tarín (2000: 14-15) adscribe a los productos audiovisuales del tipo que venimos comentando una serie de funciones que resumen por ellas mismas lo que intentamos decir, y contribuyen a desvelar los engaños de las representaciones hegemónicas:

1. Como artefactos simbólicos, mostrando y desmantelando los códigos de la producción de ficción hegemónica (MRI), estableciendo otros alternativos, propios.

2. Evidenciando los parámetros de ejercicio del poder y proponiendo otras instancias resolutivas de carácter alternativo.

3. Denunciando la ficcionalización (espectacularización) de lo real [entendido como aquello que sucede efectivamente, y no como lo innombrable] y la naturalización de lo ficticio en nuestras sociedades mediáticas.

4. Interpelando al espectador sobre su posición ante el mundo en que vive.

Concluimos esta reflexión reivindicando la posición de aquellas películas que rompen con el Modo de Representación Institucional, llegando allá donde éste cierra el paso al sujeto, hurgando en su comodidad y su seguridad como espectador, rodeándole de una neblina que le impide ver aquello mismo que le está desvelando que existe, que escapa al lenguaje, a lo descriptible, a la cultura. E infundiéndole mediante esta toma de conciencia la sospecha sobre los discursos supuestamente basados en la 
claridad de la Razón, portadores de una emancipación que lleve a la humanidad hacia un progreso indefinido, configurando una misma Historia para todos, que terminan homogeneizando por interés de quienes los configuran y los difunden.

La recuperación sutil de lo real queda en las películas de narrativa no lineal, pues, como una muestra de que estos discursos institucionalizados, hegemónicos, no pueden decirlo ni saberlo todo. En correspondencia, de alguna manera, con las siguientes palabras de Jiménez (1989: 20):

A la pregunta “¿qué somos hoy?" no podemos ya responder en términos de identidad homogénea. "Somos" muchas cosas a la vez, pero no siempre en continuidad unas con otras, con frecuencia de manera diluida o dispersa, y usualmente no de modo pleno sino fragmentario. Este es el tiempo de la pluralidad, de lo discontinuo, de la dispersión, del fragmento.

El tiempo, en definitiva, de reconocer dudas, agujeros, vacíos, heridas, impotencias. El tiempo de desvelar la quiebra de la grandilocuente soberbia con la que el ser humano alardeó de dominar el universo y a sí mismo. De arrancarle la máscara a la representación para desnudar al ventrílocuo que la sostiene.

\section{Bibliografía}

BARTHES, Roland. El tercer sentido". Lo obvio y lo obtuso: Imágenes, gestos y voces. Barcelona, Paidós, 1986.

BENJAMIN, Walter. El narrador. Madrid: Taurus, 1991.

BENJAMIN, Walter (1973): La obra de arte en la era de su reproductibilidad técnica. En Discursos Interrumpidos I. Madrid: Taurus (1ạ Edición: 1936).

BUCKLAND, Warren. Puzzle films: complex storytelling in contemporary cinema. Oxford: John Willey \& sons, 2009.

EISESTEIN, Sergei. Dickens, Griffith and the film today, 1944.

FouCAULT, Michel, El orden del discurso, Barcelona: Tusquets Editores, 1973.

Gómez TARín, Francisco Javier. Tren de Sombras de José Luis Guerín. El Cine en estado puro, Universitat de València, 2000.

GonZÁlez REQUENA, Jesús (a). Lo real la realidad y el discurso informativo en El espectáculo informativo. Madrid: Akal, 1989. 
GonzÁlez ReQuenA, Jesús (b). Lo real, la realidad, el espectáculo en El espectáculo informativo. Madrid: Akal, 1989. Pág. 73

HotToIS, Gilbert. Historia de la filosofía. Del Renacimiento a la Postmodernidad. Madrid: Cátedra, 1997.

JIMÉNEZ, José. La vida como azar. Complejidad de lo moderno, Madrid: Mondadori, 1989.

PALAO, José Antonio, La relación entre la trama y el argumento: reflexiones en torno al thriller contemporáneo, Metodologías de Análisis del Film. Madrid: Edipo, SA, 2007.

PALAO, José Antonio. El psicoanálisis y la Teoría Consensual de la Verdad: Programa para un encuentro imposible. Valencia: 1993.

PALAO, José Antonio. Hiperencuadre/Hiperrelato: Apuntes para una narratología del film postclásico. Nuevas tendencias e hibridaciones de los discursos audiovisuales contemporáneos, 2012.

PAlAO, José. Antonio. La profecía de la Imagen - Mundo. Para una genealogía del Paradigma Informativo. Valencia: IVAC, 2004.

PALAO, José Antonio. Corredores sin Ventanas, Acrobacias sin red: Linealidad narrativa e imaginario hipertextual en el cine contemporáneo, en Tortosa, Virgilio, Escrituras Digitales Tecnologías de la creación en la era virtual. Alicante: 2008.

VAtTıMo, Gianni Postmodernidad: ¿Una Sociedad Transparente? En En torno a la posmodernidad, Barcelona: Anthropos, 1990.

OUDART, Jean-Pierre. La sutura. De Baecque, Antoine. comp., 2005, Teoría y crítica del cine: avatares de una cinefilia. Barcelona: Paidós. 